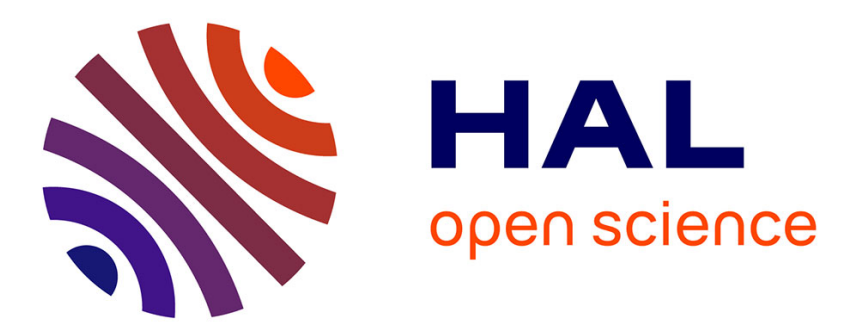

\title{
Rider Steer Torque Estimation for Motorcycle Riding Simulator
}

\author{
Lamri Nehaoua, Amine Khettat, Hichem Arioui, Hocine Imine, Stéphane
}

Espié

\section{To cite this version:}

Lamri Nehaoua, Amine Khettat, Hichem Arioui, Hocine Imine, Stéphane Espié. Rider Steer Torque Estimation for Motorcycle Riding Simulator. 5th IFAC Symposium on Mechatronics, Sep 2010, Boston, MA, United States. pp.25-31. hal-00515559

\section{HAL Id: hal-00515559 \\ https://hal.science/hal-00515559}

Submitted on 7 Sep 2010

HAL is a multi-disciplinary open access archive for the deposit and dissemination of scientific research documents, whether they are published or not. The documents may come from teaching and research institutions in France or abroad, or from public or private research centers.
L'archive ouverte pluridisciplinaire HAL, est destinée au dépôt et à la diffusion de documents scientifiques de niveau recherche, publiés ou non, émanant des établissements d'enseignement et de recherche français ou étrangers, des laboratoires publics ou privés. 


\title{
Rider Steer Torque Estimation for Motorcycle Riding Simulator
}

\author{
Lamri Nehaoua* Amine Khettat ${ }^{* *}$ Hichem Arioui * \\ Hocine Imine ${ }^{* *}$ Stéphane Espié ${ }^{* *}$ \\ * IBISC, Evry, 91020 France, \\ (e-mail: lamri.nehaoua, hichem.arioui@ibisc.univ-evry.fr). \\ ** LEPSIS, Paris, 75732, France, \\ (e-mail: amine.khettat, hocine.imine@lcpc.fr and \\ stephane.espie@inrets.fr)
}

\begin{abstract}
In this paper, we propose an estimation process for rider's torque during drive operation on simulator. The idea is basic and, in one hand, uses a DC motor as torque sensors and, on the other hand, as generator of force feedback due to tire-ground contact. The experimental implementation and analysis have revealed the effectiveness of the approach
\end{abstract}

Keywords: Motorcycle Riding Simulator, Estimation and Observation, Transportation systems.

\section{INTRODUCTION}

The use of the driving simulation seems to be an interesting alternative to answer several challenges such as: drivers training, sensitizing with the risks, the road safety, etc. This last point constitutes one of the primordial objective of our works, as for the majority of the already existing driving simulators.

The two-wheeled vehicles riders are regarded as the most vulnerable road users. Indeed, the number of motorcycle accidents has been in constant increase for several years. Moreover, according to the last statistics, in spite of the precautionary measurements as well as recently repressive installations, the number of motorcyclists killed did not drop whereas considerable progress were noted for the cars drivers.

Nowadays, simulators become an essential part in the prototyping and development and thus in various fields. One of the reasons is the fast technological progress and the increased need for competitiveness. The use of simulation became essential thanks to the possibility of carrying out representative experiments under reconfigurable conditions. The passive and active security systems (ABS, ESP, safety belts, airbags) represent a major advance in term of safety. They are more and more installed on the car vehicles and start to come up on the motorized twowheeled vehicles. It is clear that these systems have a proven effectiveness, but no information exists as for their real exploitation by the current users. Consequently, the well control of assistance systems necessarily pass by users information and training. Moreover, number of accidents are the direct cause of an riders ignorance about risks incurred in some riding situations. It thus appears necessary to develop a training tools.

Designing a simulator requires to make compromises between the fidelity of the motion restitution and the overall costs of the mechatronics architecture. If the designing of car vehicle simulators is a very active research field since many years [Chen et al. (2001); Dagdelen et al. (2004); Nehaoua et al. (2008)], the simulation of motorcycle riding remains stammering with few prototypes in the world [Ferrazzin et al. (2003); Cossalter et al. (2004)]. The question of the immersion is even more complex for a two-wheeled vehicle as well as of the balance.

In this paper we discuss the possibility of estimation the rider torque on motorcycle (riding simulator in our case). The steering rider torque constitutes an important input to the dynamic model of a two-wheeled vehicle. Moreover, the good or bad estimation of this torque significantly affects the vehicle model behavior.

Elsewhere, measuring the steer torque on motorcycle is not trivial, because of the used modern torque sensors architecture. The fact that large moment can be applied to the fork and handlebars by the ground and/or rider introduces the problem of crosstalk. The forces and moments applied to the fork will corrupt the relatively small torque measurements.

\section{OVERVIEW ON MOTORCYCLE SIMULATOR}

Within the framework of the SIMACOM project, a riding motorcycle simulator was conceived in collaboration between the INRETS-MSIS, UEVE-IBISC and IEF-UPSUD Laboratories in France. Despite its simplicity, the particularity of this simulator comes from the possibility to reproduce most of the movements and the inertial effects allowing to perceive sensations close to reality cases. This simulator has been developed for two purposes:

- as a training tool for new riders with different scenarios: normal traffic environment, dangerous riding situations (avoidance, emergency braking, nearly failing or slipping situations, bad weather conditions, etc.)

- to study riders behaviors in such situations 
Our studies have lead to an original 5 degrees of freedom (DOF) mechanical platform including a double haptic feedback on the handlebar. The three basic movements are classical and consist of pitch, roll and yaw one.

Figure 1 presents a picture of the constructed riding simulator. More details concerning the mechatronics aspects can be found here [Nehaoua et al. [2007]].

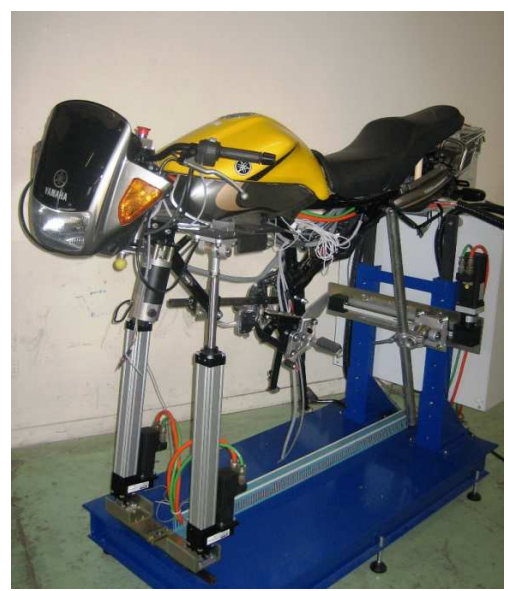

Fig. 1. The developed riding motorcycle simulator by INRETS-UEVE-UPSUD

\section{TWO-WHEELED VEHICLE DYNAMICS}

The literature of the two-wheeled vehicle dynamics is rich and even older then that of the car one, Hima et al. [2007]. Indeed, the first study, produced by Whipple, goes back to 1899 and relates to the bicycle's stability and balance [Whipple [1899]]. In 1971, a brilliant study was undertaken by Sharp [Sharp [1971]]. It examined the motorcycle's stability and its sensitivity to the variations of the geometrical and pneumatic parameters. More recently, the team of Cossalter at the university of Padova has invested itself for a few years on the development and the experimental validation of dynamic models intended for competition motorbike. The FastBike project presents a nonlinear model of the two-wheeled vehicle described like as a set of 6 bodies. It allows the simulation of 11DOF [Cossalter and Lot [2002]].

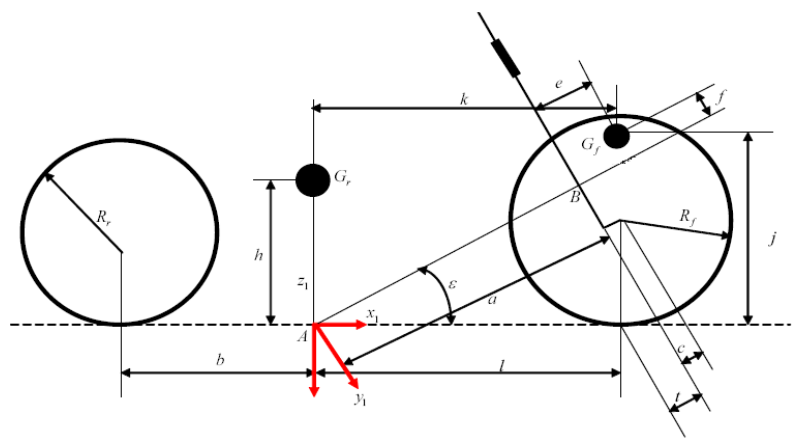

Fig. 2. Geometrical representation of the Sharp 1971 motorcycle dynamics model

However, it is not proven that the use of a complex model will increase the realism of the riding simulation. For that, we use, in a first time, the model of Sharp 1971. Its model makes it possible to simulate $4 \mathrm{DOF}$ presented as the lateral displacement, the yaw, the roll and the steer rotations. In this model, the motorcycle is represented as being a set of two rigid bodies linked together through a steering mechanism (Fig.2. The first body $G_{f}$ is the front solid composed by the front wheel, the fork and the handlebar. The second body $G_{r}$ is the rear solid including the rear wheel, the engine, the tank and the seat. Here, the rider is regarded as rigidly attached to the rear body frame and its movement is not taken into account. The motion equations are expressed by the following statespace representation:

$$
\dot{\bar{X}}_{v}=\mathcal{A}_{v} \bar{X}_{v}+\mathcal{B}_{v} \bar{u}_{v}
$$

where $\bar{X}_{v}=\left[\dot{v}, \delta, \varphi, F_{y, r}, F_{y, f}, \dot{\psi}, \dot{\delta}, \dot{\varphi}\right]^{T}$ is the state vector, $\bar{u}_{v}$ is the system input which is in our case the rider torque $\tau_{d}$ exerted on the motorcycle's handlebar.
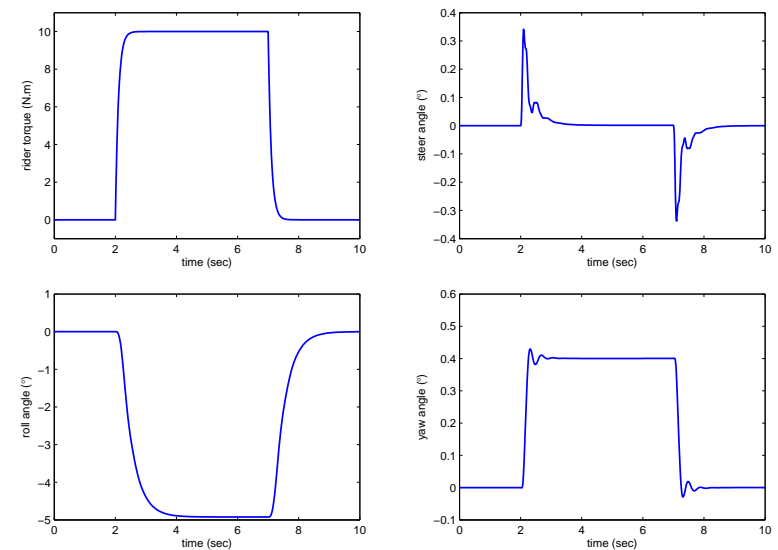

Fig. 3. Simulation of the Sharp 1971 motorcycle dynamics given as the response of $\delta, \varphi$ and $\psi$ with respect to a 10 N.m rider torque input

At $20 \mathrm{~m} / \mathrm{s}$, the minimal realization of the transfer function between the rider torque and yaw angle is given by the following equation:

$\frac{\psi(s)}{\tau_{h}(s)}=\frac{-0.055 s^{4}-3.13 s^{3}+239.4 s^{2}+2.64 \cdot 10^{4} s+4.58 \cdot 10^{4}}{d e n}$

We can observe that the transfer function has a positive zero at 78.349 , then, a non-minimum phase behavior which corresponding to the counter steering phenomenon to ride a motorcycle into a turn (Fig.3). This phenomenon is one of the most important scheme which the simulator should be able to reproduce.

\section{INTERFACING THE VIRTUAL DYNAMICS MODEL AND THE TORQUE FEEDBACK SYSTEM}

\subsection{System description and modeling}

Contrary to a car vehicle, the simulation of the virtual two-wheeled dynamics model requires a precise knowledge of the rider's torque applied on the simulator's handlebar. However, in the lack of a handlebar torque sensor, rider's torque must be estimated. 
In the present simulator, the front wheel and fork are replaced by a DC motor, only the handlebar is keeped. This resulting configuration, handlebar and motor, is considered as the new interface system between the rider on simulator and the virtual motorcycle presented herein by the dynamics model. The DC motor aims, in one hand to give a real riding sensation by a torque feedback and in the other hand, to estimate the rider torque.

The implemented restitution system is composed of several stages (fig.4), described as:

- An original Yamaha $125 \mathrm{~cm}^{3}$ motorcycle handlebar.

- The handlebar is attached to the DC motor axis through a double pulley-belt to increase the produced torque.

- An optical encoder for the measurement of the steer angle. This sensor is mounted in parallel axes through a pully-belt system with respect to the DC motor shaft axis to improve the resolution of the rotation measure.

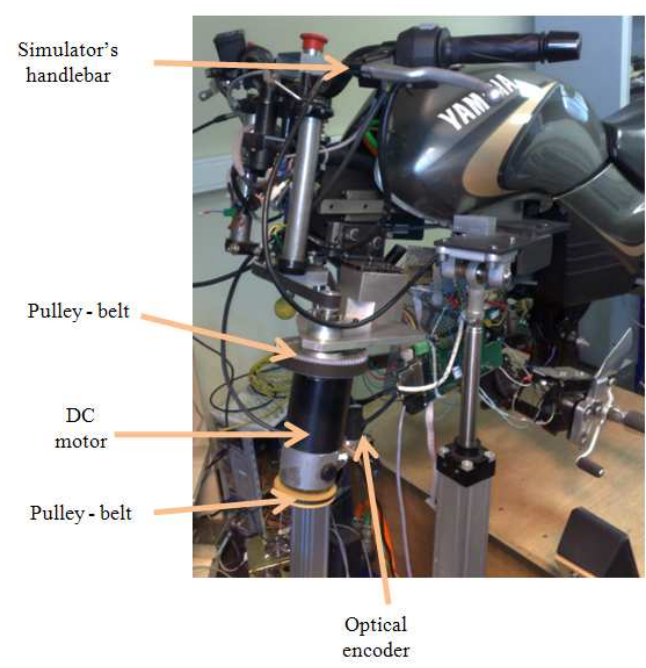

Fig. 4. Torque feedback system implemented on the riding simulator

In order to model the handlebar-reduction-actuator system, we start by writing the electrical equation of the DC motor which is given by:

$$
u-e=R i+L \frac{d i}{d t}
$$

Here, $u, e$ are respectively the control and back electromotrice voltages. $R, L$ are the resistance and inductance of the DC motor. $i$ is the measured motor current.

Next, the equation describing the mechanical behavior of the DC motor is given by:

$$
J_{m} \ddot{\theta}_{m}+\beta_{m} \dot{\theta}_{m}=\tau_{m}-\tau_{c m}
$$

where $J_{m}, \beta_{m}$ are the inertia and the damping of the motor's rotor. $\theta_{m}$ is the rotor axis rotation. $\tau_{m}, \tau_{c m}$ are respectively the actuation torque and the load torque as viewed in the motor side.

After, the dynamics of handlebar system can be written by the following equation:

$$
J_{h} \ddot{\theta}_{h}+\beta_{v, h} \dot{\theta}_{h}+\beta_{s} \operatorname{sign}\left(\dot{\theta}_{h}\right)=\tau_{h}+\tau_{d}
$$

where $J_{h}, \beta_{v, h}, \beta_{s}$ are the inertia, viscous and dry damping of the handlebar. $\theta_{h}$ is the handlebar steer angle. $\tau_{d}=$ $N_{1} \tau_{c m}$ is load torque as felt at the handlebar side and $N_{1}$ is the double pulley-belt ratio. Knowing that $\theta_{m}=N_{1} \theta_{h}$, $\tau_{m}=k_{t} i$ and $e=k_{e} \dot{\theta}_{m}$, then:

$$
\begin{aligned}
& J_{e q} \ddot{\theta}_{h}+\beta_{e q} \dot{\theta}_{h}+\beta_{s} \operatorname{sign}\left(\dot{\theta}_{h}\right)=\tau_{h}+N_{1} k_{t} i \\
& L \frac{d i}{d t}+R i=u-k_{e} N_{1} \dot{\theta}_{h}
\end{aligned}
$$

where, $J_{e q}=J_{h}+N_{1}^{2} J_{m}$ and $\beta_{e q}=\beta_{v, h}+N_{1}^{2} \beta_{m}$.

Equation (5) constitutes the electrical and mechanical dynamics representation of the restitution system. In this equation, $J_{h}, \beta_{m}, k_{t}, k_{e}$ and $N_{1}$ are well identified parameters.

\subsection{Identification}

Identification of the simulator's handlebar parameters is of crucial importance in the estimation of the rider torque and hence, to drive the simulator. Herein, we look for the estimation of the handlebar's inertia $J_{m}$ and friction parameters $\beta_{v, h}, \beta_{s}$.

In the identification process, the reference input is the analog voltage representing the speed signal and the output is the angular velocity of the motor, which is obtained by differentiation of the encoder signals. Rider torque is set to be zero.

First, equation (5) must be written in a linear form with respect to parameters to be estimated. By neglecting the DC motor inductance, equation (5) can be expressed like following:

$$
J_{e q} \ddot{\theta}_{h}+\beta_{e q}^{\prime} \dot{\theta}_{h}+\beta_{s} \operatorname{sign}\left(\dot{\theta}_{h}\right)=\frac{N_{1} k_{t}}{R} u
$$

where $\beta_{e q}^{\prime}=\beta_{e q}+\frac{N_{1}^{2} k_{t} k_{e}}{R}$. From equation (6), we can deduce the following parametric expression:

$$
\Phi \bar{p}=\frac{k_{t}}{R} u
$$

where $\bar{p}=\left[J_{e q}, \beta_{e q}^{\prime}, \beta_{s}\right]^{T}$ is the vector of the different parameters to be identified and $\Phi=\left[\ddot{\theta}_{h}, \dot{\theta}_{h}, \operatorname{sign}\left(\dot{\theta}_{h}\right)\right]$.

Several methods were developed in the literature for the parametric identification. We choose the adaptive gradient method owing to its simplicity in off-line or on-line implementation [Craig (1988)]. This method consists of optimizing a quadratic cost function $C_{f}=\frac{1}{2}\left(\tau_{r e f}-\tau\right)^{2}$, where $\tau_{\text {ref }}=\frac{N_{1} k_{t}}{R} u$ and $\tau=\Phi \bar{p}$. Adaptation law is characterized by:

$$
\dot{\bar{p}}=-\mathcal{K} \Phi^{T}\left(\frac{k_{t}}{R} u-\Phi \bar{p}\right)
$$

where $\mathcal{K}$ is adaptation matrix coefficients adjusted to ensure rapid convergence and also tied to the different excitation trajectories (slow or rapid reference trajectory). Finally, the different parameters are obtained by integrating $\dot{\bar{p}}$ of equation (8).

Experimental identification is carried out using a voltage input signal of type chirp sine with a frequency interval of $[0.1 \mathrm{~Hz}-2 \mathrm{~Hz}]$ and amplitude of 3 Volt. The angular 
position is acquired by CAN bus at a sampling rate of $100 \mathrm{~Hz}$. Physical identified parameters are summarized in the following table1.
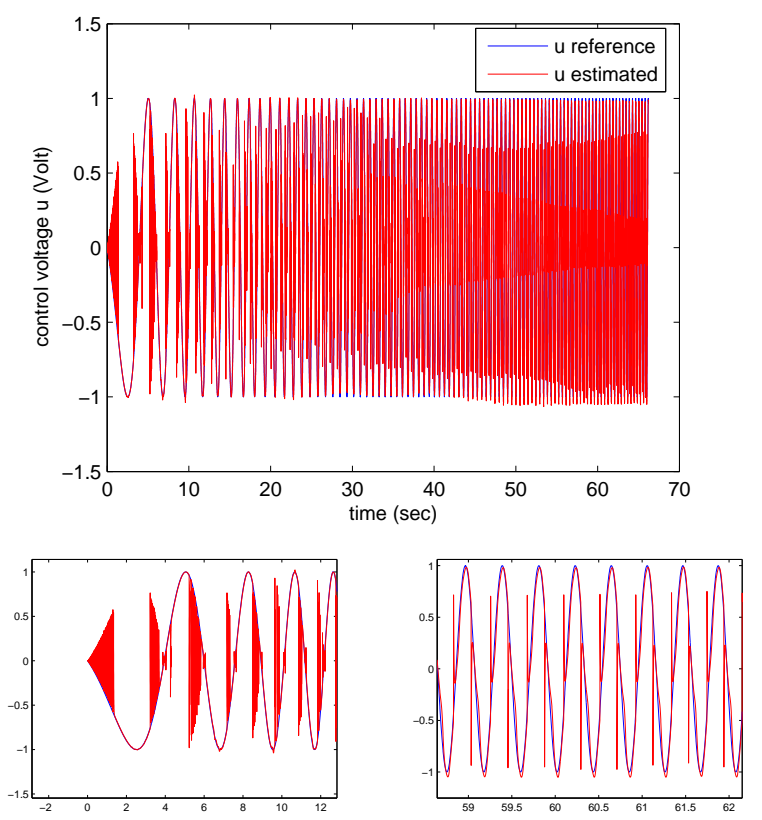

Fig. 5. Simulation validation using a chirp sine $0.1-4 \mathrm{~Hz}$ input voltage and a zoom underlining the chattering caused by the sign function

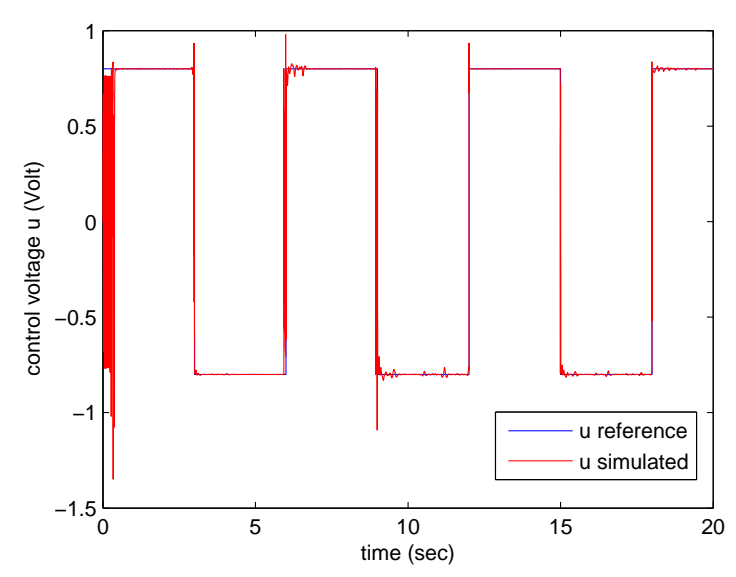

Fig. 6. Simulation validation using a bipolar rectangular input voltage

Figures 5 and 6 show a simulation validation of dynamics equation (5) using the estimated parameters. In this case the voltage input is set to be respectively a chirp sine with a frequency interval of $[0.1 \mathrm{~Hz}-4 \mathrm{~Hz}]$ and a bipolar rectangular signal, both with amplitude of 1 Volt. Regardless the some numerical problem caused by the sign function, we can confirm the effectiveness of the identification process.

\subsection{Rider torque estimation}

After having identified the various parameters of the restitution system, it is now possible to estimate the rider

\begin{tabular}{|c|c|c|}
\hline inertia $J_{h}$ & dry friction $\beta_{s}$ & viscous friction $\beta_{v, h}$ \\
\hline 0.0415 & 1.734 & 13.956 \\
\hline
\end{tabular}

Table 1. Friction and Inertial estimated parameters

torque exerted on the simulator's handlebar. The main objective is that the rider on simulator would be able to drive a virtual motorcycle as close as possible like a real one. This means that the restitution system should behave closely to a reference model described, in our case, by the motorcycle dynamics model. Moreover, the motor must provide a judicious torque restitution to the rider and that in full scale. So, from equation (1), the reference model generates the desired handlebar position $\delta$ and velocity $\dot{\delta}$ as following:

$$
\begin{aligned}
& \dot{\bar{X}}_{v}=\mathcal{A}_{v} \bar{X}_{v}+\mathcal{B}_{v} \tau_{h} \\
& {\left[\begin{array}{c}
\delta \\
\dot{\delta}
\end{array}\right]=\mathcal{C}_{v} \bar{X}_{v}}
\end{aligned}
$$

and equation (5) governing the simulator's handlebar dynamics is given by:

$$
\begin{aligned}
& J_{e q} \ddot{\theta}_{h}+\beta_{e q} \dot{\theta}_{h}=\tau_{h}-\tau_{s p}+N_{1} k_{t} i \\
& L \frac{d i}{d t}+R i=u-k_{e} N_{1} \dot{\theta}_{h}
\end{aligned}
$$

where $\tau_{s p}=\beta_{s} \operatorname{sign}\left(\dot{\theta}_{h}\right)$ is considered as an input perturbation. It follows that the nominal system $G_{n}$ can be expressed by the following state-space representation:

$$
\dot{\bar{X}}_{n}=\mathcal{A}_{n} \bar{X}_{n}+\mathcal{B}_{n} \bar{U}
$$

where, $\bar{X}_{n}=\left[\dot{\theta}_{h}, i, \theta_{h}\right]^{T}$ is the state vector, $\bar{U}=$ $\left[\tau_{d}, u, \tau_{s p}\right]^{T}$ is the inputs vector and:

$$
\mathcal{A}_{n}=\left[\begin{array}{ccc}
-\frac{\beta_{e q}}{J_{e q}} & \frac{N_{1} k_{t}}{J_{e q}} & 0 \\
-\frac{N_{1} k e}{L} & -\frac{R}{L} & 0 \\
1 & 0 & 0
\end{array}\right] \quad \mathcal{B}_{n}=\left[\begin{array}{ccc}
\frac{1}{J_{e q}} & 0 & -\frac{1}{J_{e q}} \\
0 & \frac{1}{L} & 0 \\
0 & 0 & 0
\end{array}\right]
$$

Once the reference signals $\delta$ and $\dot{\delta}$ are generated, the DC motor can be controlled either in torque or in position. The second method (Fig.7) is well adapted to observe the rider torque. Then, we look for the determination of position a controller such that:

$$
\left|\delta-\theta_{h}\right| \approx \epsilon
$$

A classical PID controller is chosen to achieve this purpose. The open-loop transfer function between the simulator's handlebar angle $\theta_{h}$ and the control voltage $u$ is given by:

$$
\frac{\theta_{h}(s)}{U(s)}=C(s) \frac{1}{s} \frac{1}{\frac{J_{e q}}{N_{1} k_{t}} s^{2}+\frac{J_{e q} R+\beta_{e q} L}{N_{1} k_{t}} s+N_{1} k_{e}}
$$

and the sensitivity transfer between the simulator's handlebar angle $\theta_{h}$ and the perturbation torque is expressed by:

$$
\frac{\theta_{h}(s)}{\tau_{s p}(s)}=C(s) \frac{L s+R}{s} \frac{1}{\frac{J_{e q}}{N_{1} k_{t}} s^{2}+\frac{J_{e q} R+\beta_{e q} L}{N_{1} k_{t}} s+N_{1} k_{e}}
$$

where $C(s)=K_{p}+\frac{K_{i}}{s}+K_{d} s$ is the PID transfer function. 


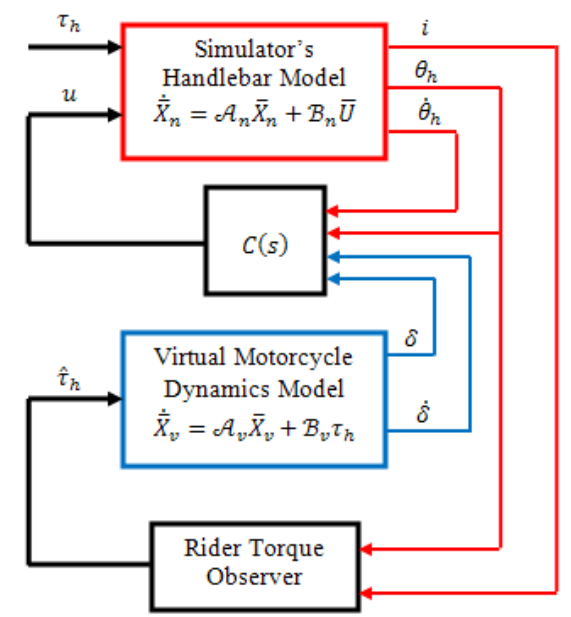

Fig. 7. Interfacing the virtual dynamics model and the torque feedback system

The next step is to estimate the unknown rider torque $\tau_{h}$. This torque can be computed directly from equation (10) as bellow:

$$
\tau_{h}=J_{e q} \ddot{\theta}_{h}+\beta_{e q} \dot{\theta}_{h}+\tau_{s p}-N_{1} k_{t} i
$$

Nevertheless, this method requires a numerical twice differentiation of the position angle measure. An other method consist of the use of an observer to estimate the rider torque as an unknown input from position and current measurements. To this end, we re-write the equation (11) by introducing the observer dynamics, so:

$$
\dot{\bar{X}}_{o}=\mathcal{A}_{o} \hat{\bar{X}}_{o}+\mathcal{B}_{o} \bar{U}^{\prime}+\mathcal{L}_{o}\left[\begin{array}{c}
\theta_{h}-\hat{\theta}_{h} \\
i-\hat{i}
\end{array}\right]
$$

and

$$
\left[\begin{array}{c}
\hat{\theta}_{h} \\
\hat{i}
\end{array}\right]=\mathcal{C}_{o} \hat{\bar{X}}_{o}
$$

where $\hat{\bar{X}}_{o}=\left[\dot{\hat{\theta}}_{h}, \hat{i}, \hat{\theta}_{h}, \hat{\tau}_{h}\right]^{T}$ is the observer's state vector. $\bar{U}^{\prime}=\left[u, \tau_{s p}\right]^{T}$ is the new input vector and $\theta_{h}, i$ are the measured variables. The pair $\left(\mathcal{A}_{o}, \mathcal{C}_{o}\right)$ is of full rank then the system $(17,18)$ is observable, so the observer dynamics can then be expressed as:

$$
\dot{\bar{X}}_{o}=\left(\mathcal{A}_{o}-\mathcal{L}_{o} \mathcal{C}_{o}\right) \hat{\bar{X}}_{o}+\left[\begin{array}{ll}
\mathcal{B}_{o} & \mathcal{L}_{o}
\end{array}\right]\left[\begin{array}{c}
\bar{U}^{\prime} \\
\theta_{h} \\
i
\end{array}\right]
$$

Finally, observer matrix gain $\mathcal{L}_{o}$ are computed by a pole placement to ensure a time response of $0.2 \mathrm{~s}$ and an overshoot less than $5 \%$.

\section{VALIDATION OF THE OBSERVER PERFORMANCE}

Figures 8 and 9 show a simulation validation of the observer dynamics and thus for an input rider torque of 10 N.m. In the first figure (Fig.8), we have traced the estimated torque $\hat{\tau}_{h, 1}$ as computed from equation (16) and the observed torque as $\hat{\tau}_{h, 2}$ obtained by the use of the observer equation (19).

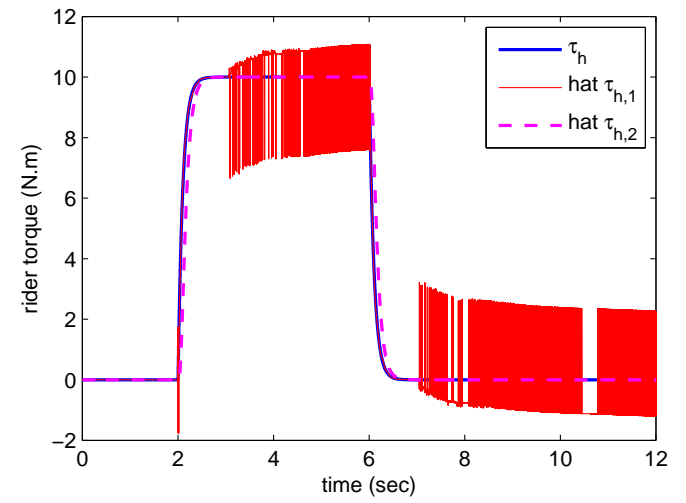

Fig. 8. Simulation validation of the observer dynamics. $\tau_{h}$ is the reference rider torque. $\hat{\tau}_{h, 1}$ is the estimated torque using equation (16). $\hat{\tau}_{h, 2}$ is the estimated torque using the observer dynamic equation (19)

Even that equation (16) provides a consistent estimation, the use of the observer eliminates the numerical problems caused by the sign function an compute an estimation very close to the real torque. Figure 9 present the position tracking performance between the reference position $\delta$ and the simulator's handlebar position $\theta_{h}$.

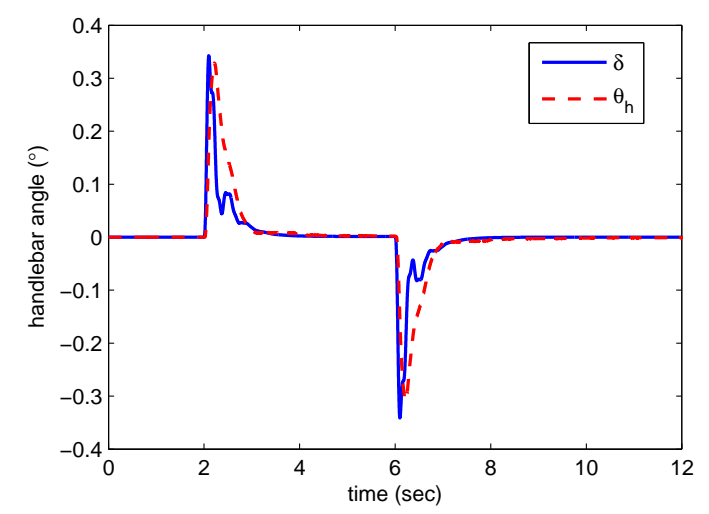

Fig. 9. PID tracking performance of the reference position

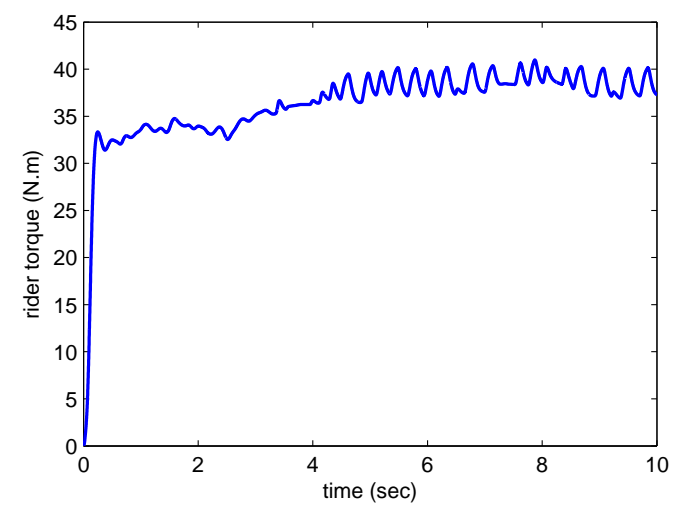

Fig. 10. Experimental validation of the observer dynamics - Estimated rider torque 
Figures 10, 11 and 12 show an experimental validation of the observer dynamics. In this case, the simulator's handlebar turns freely in response to a 40\%, 5 Volt, PWM excitation and blocked by the rider. After, angular position and actuation current are measured and acquired by a CAN bus at a samling rate of $100 \mathrm{~Hz}$. Figure 10 presents the estimated rider torque where figures 11 and 12 show the estimated angular position $\hat{\theta}_{h}$ and motor current $\hat{i}$.

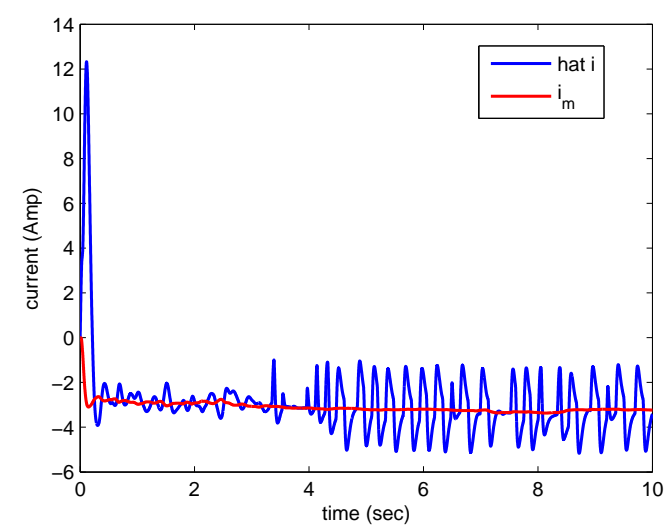

Fig. 11. Comparison between the estimated motor current $\hat{i}$ and measured one

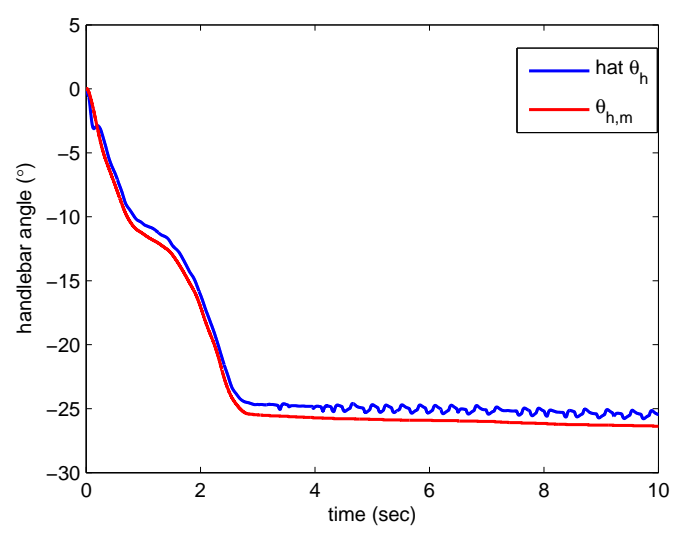

Fig. 12. Comparison between the estimated angular position $\hat{\theta}_{h}$ and measured one

\section{CONCLUSION}

In this paper we present an approach for rider's torque estimation (torque applied on the handlebar of the simulator) based, in one hand, on Lumberger observation technique and, on the other hand, on the collected data from DC motor. This last is used as force feedback interface linked to the handlebar. The well known simulator fork (set handlebar-actuator) model is necessary for the observation technique. To this end, the electric-dynamic model is done by introducing dry and viscous frictions.

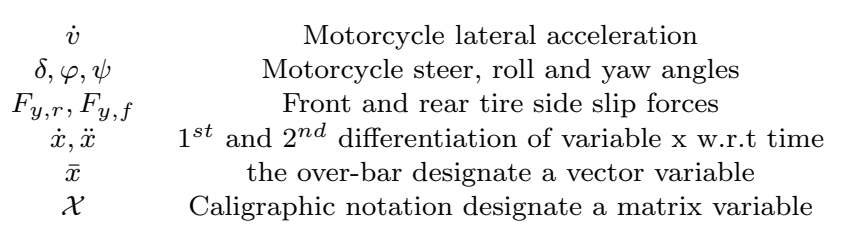

\section{NOMENCLATURE}

\section{ACKNOWLEDGEMENTS}

This work has been supported by the french ANR R\&D program, DAMOTO. Authors would like to thank Stéphane Caro, Researcher engineer at LEPSIS for his help in conducting the experiments.

\section{REFERENCES}

Chen, L., Papelis, Y., Waston, G., and Solis, D. (2001). NADS at the University of Iowa: A tool for driving safety research. In Proceedings of 1st Human Centered Transprotation Simulation Conference. Iowa, USA.

Cossalter, V., Doria, A., and Lot, R. (2004). Development and validation of a motorcycle riding simulator. In World Automotive Congress FISITA. Barcelona, Spain.

Cossalter, V. and Lot, R. (2002). A motorcycle multibody model for real time simulation based on the natural coordinates approach. Vehicle System Dynamics, 37(6), 423-447.

Craig, J. (1988). Adaptive Control of Mechanical Manipulators. Addison-Wesley Publishing Company. ISBN 0-201-10490-3.

Dagdelen, M., Reymond, G., Kemeny, A., Bordier, M., and Maza, N. (2004). MPC based motion cueing algorithm: Development and application to the ULTIMATE driving simulator. In Driving Simulation Conference DSC Europe 2004, 221-233. Paris-France.

Ferrazzin, D., Barbagli, F., Avizzano, C., Pietro, D.D., and Bergamasco, M. (2003). Designing new commercial motorcycles through a highly reconfigurable virtual reality-based simulator. Advanced Robotics, 17(4), 293318.

Hima, S., Nehaoua, L., Seguy, N., and Arioui, H. (2007). Motorcycle dynamic model synthesis for two wheeled driving simulator. In $10^{\text {th }}$ International IEEE Conference on Intelligent Transportation Systems (ITSC'07), 812-817.

Nehaoua, L., Arioui, H., Seguy, N., and Espie, S. (2007). Design and modeling of a new motorcycle riding simulator. In American Control Conference (ACC'O'7), 176181.

Nehaoua, L., Mohellebi, H., Amouri, A., Arioui, H., Espié, S., and Kheddar, A. (2008). Design and control of a small-clearance driving simulator. IEEE Transactions on Vehicular Technology, 57(1), 736-746.

Sharp, R. (1971). The stability and control of motorcycles. Journal of Mechanical Engineering Science, 13, 316329.

Whipple, F. (1899). Stability of the motion of a bicycle. Quarterly Journal of Pure and Applied Mathematics, 30. 